\title{
Sex differences in the association between major cardiovascular risk factors in midlife and dementia: a cohort study using data from the UK Biobank
}

\author{
Jessica Gong ${ }^{1 *}$ D, Katie Harris', Sanne A. E. Peters ${ }^{1,2,3}$ and Mark Woodward ${ }^{1,2,4}$
}

\begin{abstract}
Background: Sex differences in major cardiovascular risk factors for incident (fatal or non-fatal) all-cause dementia were assessed in the UK Biobank. The effects of these risk factors on all-cause dementia were explored by age and socioeconomic status (SES).

Methods: Cox proportional hazards models were used to estimate hazard ratios (HRs) and women-to-men ratio of HRs (RHR) with 95\% confidence intervals (Cls) for systolic blood pressure (SBP) and diastolic blood pressure (DBP), smoking, diabetes, adiposity, stroke, SES and lipids with dementia. Poisson regression was used to estimate the sexspecific incidence rate of dementia for these risk factors.

Results: 502,226 individuals in midlife (54.4\% women, mean age 56.5 years) with no prevalent dementia were included in the analyses. Over 11.8 years (median), 4068 participants ( $45.9 \%$ women) developed dementia. The crude incidence rates were 5.88 [95\% Cl 5.62-6.16] for women and 8.42 [8.07-8.78] for men, per 10,000 personyears. Sex was associated with the risk of dementia, where the risk was lower in women than men $(H R=0.83[0.77-$ 0.89]). Current smoking, diabetes, high adiposity, prior stroke and low SES were associated with a greater risk of dementia, similarly in women and men. The relationship between blood pressure (BP) and dementia was U-shaped in men but had a dose-response relationship in women: the HR for SBP per $20 \mathrm{mmHg}$ was 1.08 [1.02-1.13] in women and 0.98 [0.93-1.03] in men. This sex difference was not affected by the use of antihypertensive medication at baseline. The sex difference in the effect of raised BP was consistent for dementia subtypes (vascular dementia and Alzheimer's disease).

Conclusions: Several mid-life cardiovascular risk factors were associated with dementia similarly in women and men, but not raised BP. Future bespoke BP-lowering trials are necessary to understand its role in restricting cognitive decline and to clarify any sex difference.
\end{abstract}

Keywords: Sex difference, Risk factor, Dementia, UK Biobank

\footnotetext{
* Correspondence: jgong@georgeinstitute.org.au

${ }^{1}$ The George Institute for Global Health, University of New South Wales, Level 5, 1 King St, Newtown, NSW 2042, Australia

Full list of author information is available at the end of the article
}

C C The Author(s). 2021 Open Access This article is licensed under a Creative Commons Attribution 4.0 International License, which permits use, sharing, adaptation, distribution and reproduction in any medium or format, as long as you give appropriate credit to the original author(s) and the source, provide a link to the Creative Commons licence, and indicate if changes were made. The images or other third party material in this article are included in the article's Creative Commons licence, unless indicated otherwise in a credit line to the material. If material is not included in the article's Creative Commons licence and your intended use is not permitted by statutory regulation or exceeds the permitted use, you will need to obtain permission directly from the copyright holder. To view a copy of this licence, visit http://creativecommons.org/licenses/by/4.0/. The Creative Commons Public Domain Dedication waiver (http://creativecommons.org/publicdomain/zero/1.0/) applies to the data made available in this article, unless otherwise stated in a credit line to the data. 


\section{Background}

Dementia is a fast-growing global epidemic-predominately driven by the steep increase of population ageing $[1,2]$ - posing immense pressure on the public health, social care and fiscal systems [3]. Around 50 million people are living with dementia globally [4], and this is projected to triple by 2050 [2]. The most recent agestandardised global prevalence and death rate related to dementia were both higher in women than men in 2016 [1].

Cardiovascular risk factors are increasingly recognised as contributors to dementia [3], associated with greater risk not only for vascular dementia but also dementia of the Alzheimer's type $[5,6]$. While some cardiovascular risk factors confer differential excess risks on diseases such as myocardial infarction [7] and stroke [8] for women and men, sex differences in the effect of major cardiovascular risk factors for dementia are not well characterised.

Providing that sex is an important modifier for many diseases including Alzheimer's disease [9], this study sought to examine the sex differences in the association between major cardiovascular risk factors and the risk of all-cause dementia in the UK Biobank. We also assessed whether sex differences varied across age groups and socioeconomic status.

\section{Methods}

The UK Biobank is a large population-based prospective cohort study that recruited 502,489 individuals ages 4069 , between 2006 and 2010 [10]. Individuals aged 40 to 69 were invited to attend one of the 22 centres for baseline assessment, which included questionnaires soliciting lifestyle and medical history, physical and functional measurements. Written informed consent was obtained for all participants electronically. The present analyses excluded participants with prevalent dementia at baseline $(N=263)$. Follow-up for all participants involved linkage with hospital admissions data from England, Scotland, and Wales and the national death register to identify the date of the first known diagnosis of dementia after the date of baseline assessment. Death data and hospital inpatient data were censored on the 30 November 2020, or when death, fatal or non-fatal dementia was recorded, which yielded a median follow-up time of 11.77 years for women and 11.73 years for men.

\section{Measurement of risk factors}

We examined the associations with incident all-cause dementia for a range of major cardiovascular risk factors: blood pressure (systolic blood pressure (SBP), diastolic blood pressure (DBP)), smoking status and intensity, diabetes mellitus (type 1 and type 2), adiposity (body mass index (BMI), waist circumference (WC), waist-to-hip ratio (WHR) and waist-to-height ratio (WHTR)), prior stroke, socioeconomic status (SES) and lipids (total cholesterol, high-density lipoprotein (HDL) cholesterol and low-density lipoprotein (LDL) cholesterol).

Blood pressure was taken at baseline using the Omron HEM-7015IT digital blood pressure monitor by taking the mean of two sitting measures. Based on the American Heart Association (AHA) 2017 guidelines [11], we categorised blood pressure into four groups (normal: $\mathrm{SBP}<120 \mathrm{mmHg}$ and $\mathrm{DBP}<80 \mathrm{mmHg}$; elevated: SBP $120-129 \mathrm{mmHg}$ and DBP < $80 \mathrm{mmHg}$; stage 1 hypertension: SBP 130-139 mmHg or DBP $80-89 \mathrm{mmHg}$; stage 2 hypertension: $\mathrm{SBP} \geq 140 \mathrm{mmHg}$ or $\mathrm{DBP} \geq 90 \mathrm{mmHg}$ ). Smoking status was self-reported and categorised as never, former, or current smokers. Daily consumption of cigarettes was collected among current smokers. Selfreported diabetes was recorded: if the age at diagnosis was less than 30, and the participant was using insulin, it was classified as having type 1 diabetes, otherwise as type 2 diabetes. BMI was calculated as the weight of the individual in kilogrammes, measured using the Tanita BC-418 MA body composition analyser, divided by the square of the individual's standing height in metres. BMI was used as a continuous measure, as well as categorised into four groups (underweight: $<18.5 \mathrm{~kg} / \mathrm{m}^{2}$; healthy weight: $18.5-24.9 \mathrm{~kg} / \mathrm{m}^{2}$; overweight: $25.0-29.9 \mathrm{~kg} / \mathrm{m}^{2}$; obese: $30.0 \mathrm{~kg} / \mathrm{m}^{2}$ and above). Waist and hip circumference were measured using the Wessex non-stretchable sprung tape measure. History of stroke was selfreported, based on a touchscreen questionnaire, and a nurse-led interview was conducted to confirm the medical history. SES was determined using the Townsend Deprivation Index and categorised into three levels using the national cut-off points (high $\leq-2.08$; middle -2.08 -1.40 ; low $\geq 1.40$ ). The Townsend Deprivation Index is a measure of area deprivation, derived from the national census data about unemployment, car ownership, household overcrowding and owner occupation, with higher scores indicate higher levels of deprivation [12]. Blood lipid levels were measured using the Beckman Coulter AU580, and elevated cholesterol was defined as total cholesterol $\geq 6.2 \mathrm{mmol} / \mathrm{L}$.

\section{Dementia outcome}

The primary study endpoint was incident fatal or nonfatal all-cause dementia. The International Classification of Diseases ICD-10 codes (A81.0, F00, F01, F02, F03, F05, G30, G31.0, G31.1, G31.8, and I67.3) were used to identify participants with dementia if one or more of these codes were recorded as a primary or secondary diagnosis in the health records or recorded as the underlying or contributory cause of death in the death registers. Outcome adjudication for incident dementia was conducted by the UK Biobank Outcome Adjudication 
Group, and ICD-10 codes were used to determine Alzheimer's disease (AD) (F00, G30) and vascular dementia (F01, I67.3).

\section{Statistical analysis}

Baseline characteristics for women and men were presented as number (percentage) for categorical variables and as mean (standard deviation) for continuous variables. The crude incidence of all-cause dementia was modelled using Poisson regression, with sex as a covariate and a log offset for person-years. Cox proportional hazards regression models were used to estimate the sex-specific hazard ratios (HR) and 95\% confidence intervals (CI) for each risk factor for dementia, with interaction terms fitted between each exposure variable and sex [13].

Analyses for all risk factors were adjusted for age, with different sets of covariates, determined a priori, for each risk factor according to perceived probable causal relationships. All models were adjusted for age. In addition, SBP, diabetes, socioeconomic status and total cholesterol were adjusted for each other, and adjusted for smoking status, BMI, lipid-lowering drugs and antihypertensive drugs. For DBP and AHA hypertension, the same adjustments were made as SBP. Stroke and smoking variables were adjusted for socioeconomic status. Body adiposity was adjusted for smoking status and socioeconomic status. HDL and LDL cholesterol were adjusted the same way as total cholesterol. The interaction term between each risk factor and sex was used to obtain the womento-men ratio of hazard ratios (RHR) for each risk factor [13]. The effects of the risk factors were evaluated separately for vascular dementia and AD using Cox models, with the same adjustments used in the main analyses.

We conducted subgroup analyses investigating whether sex differences in risk factors for dementia varied by age group ( $<60$ years and $\geq 60$ years). Similarly, subgroup analyses were undertaken by SES groups, categorising individuals as above or below the national median Townsend score in the UK $(-0.56)$.

In addition to making relative comparisons, we evaluated sex differences on the absolute scale, by estimating sex-disaggregated unadjusted and multiple-adjusted rates per 10,000 person-years, and the women-to-men difference of the rate differences, using Poisson regression models. Covariate adjustments were the same as those made in the Cox models.

Post-hoc exploratory analyses were conducted after observing unexpected results from the initial analyses for blood pressure and BMI. We assessed the shape of the associations for continuous SBP, DBP and BMI, with the risk of dementia for women and men using penalised smoothing splines, adjusted for the same set of covariates as outlined for the Cox models. Extreme values in the upper and lower $0.1 \%$ of the blood pressure and BMI distributions, which are associated with unreliable estimates, were omitted. The reference was $120.0 \mathrm{mmHg}$ for SBP, $80.0 \mathrm{mmHg}$ for DBP and $22.5 \mathrm{~kg} / \mathrm{m}^{2}$ for BMI. Sex differences in blood pressure were further explored by disaggregating the results by baseline antihypertensive use.

Kaplan-Meier survival curves were additionally constructed to assess the survival probability of death and dementia by sex.

Sensitivity analysis was conducted, by fitting the proportional sub-distribution hazards regression model described by Fine and Grey [14], in which death was considered as a competing risk.

All analyses were performed on complete case data using R Studio Version 4.0.2 (R Core Team, 2020) and Stata 16.0 (StataCorp, 2019).

\section{Results}

A total of 502,226 individuals (54.4\% women) without a prior diagnosis of dementia were included in the analyses. The mean age of participants was 56.3 years (standard deviation $(\mathrm{SD})=8.0$ ) for women and 56.7 years $(\mathrm{SD}=8.2)$ for men (Table 1). On average, women had lower SBP and DBP and a lower percentage of women than men had diabetes and stroke at study baseline.

Over a median 11.8 years follow-up, 4068 (1866 women) cases of incident all-cause dementia were documented.

\section{Sex comparison of risk factor associations}

Sex was a significant risk factor for dementia, with women at a lower risk of dementia than men (HR, 0.83 [0.77-0.89]) after multiple adjustments of systolic blood pressure, baseline age, smoking status, lipids medications, total cholesterol, antihypertensive medications, body mass index, diabetes and Townsend deprivation index.

The age-adjusted HRs (see Additional file 1) are broadly similar to the multiple adjusted HRs (Fig. 1), although the associations between lipids and dementia were no longer significant after multiple adjustments.

\section{Blood pressure}

Higher values of SBP were associated with a greater risk of dementia in women (HR, 1.08 [1.02-1.13] per 20 $\mathrm{mmHg})$, but not in men $(0.98$ [0.93-1.03]); DBP was associated with lower risk of dementia in men $(0.92$ [0.880.97 ] per $10 \mathrm{mmHg}$ ), but not in women $(1.01$ [0.961.07]). Compared with normal blood pressure, men had a lower risk of dementia in different stages of hypertension, whereas the risk increased as hypertension stages worsen in women. The spline analysis suggested that the $\mathrm{HR}$ of dementia in women tended to increase with SBP, 
Table 1 Baseline characteristics of women and men in UK Biobank

\begin{tabular}{|c|c|c|}
\hline Characteristics & Women $(n=273,262)$ & Men $(n=228,964$ \\
\hline Age (years) (mean (SD)) & $56.3(8.0)$ & $56.7(8.2)$ \\
\hline \multicolumn{3}{|l|}{ Ethnicity: } \\
\hline White & $257,320(94.2)$ & $215,111(93.9)$ \\
\hline Other & $14,678(5.8)$ & $12,344(6.1)$ \\
\hline \multicolumn{3}{|l|}{ Blood pressure $(\mathrm{mmHg})$ : } \\
\hline Systolic (mean (SD)) & $135.3(19.2)$ & $140.9(17.5)$ \\
\hline Diastolic (mean (SD)) & $80.7(10.0)$ & $84.1(10.0)$ \\
\hline \multicolumn{3}{|l|}{ AHA hypertension categories: } \\
\hline Normal & $55,316(20.2)$ & $20,020(8.7)$ \\
\hline Elevated & $35,561(13.0)$ & $26,008(11.4)$ \\
\hline Stage 1 hypertension & $72,038(26.4)$ & $62,661(27.4)$ \\
\hline Stage 2 hypertension & $109,578(40.1)$ & $119,722(52.3)$ \\
\hline \multicolumn{3}{|l|}{ Smoking status: } \\
\hline Never smoker & $161,979(59.3)$ & $111,404(48.7)$ \\
\hline Former smoker & $85,412(31.3)$ & $87,535(38.2)$ \\
\hline Current smoker & $24,359(8.9)$ & $28,593(12.5)$ \\
\hline \multicolumn{3}{|l|}{ By smoking intensity: } \\
\hline 1-9 cigarettes per day & $4397(18.1)$ & $2805(9.8)$ \\
\hline 10-19 cigarettes per day & $8440(34.7)$ & $6996(24.5)$ \\
\hline$\geq 20$ cigarettes per day & $5590(22.9)$ & $7908(27.7)$ \\
\hline Not reported & $5932(24.4)$ & $10,884(38.1)$ \\
\hline \multicolumn{3}{|l|}{ Diabetes: } \\
\hline Type 1 diabetes* & $564(0.2)$ & $652(0.3)$ \\
\hline Type 2 diabetes & $9946(3.6)$ & $15,514(6.8)$ \\
\hline \multicolumn{3}{|l|}{ Body mass index $\left(\mathrm{kg} / \mathrm{m}^{2}\right)$ : } \\
\hline Body mass index (mean (SD)) & $27.1(5.2)$ & $27.8(4.2)$ \\
\hline \multicolumn{3}{|l|}{ BMI categories: } \\
\hline Underweight $(<18.5)$ & $2079(0.8)$ & $547(0.2)$ \\
\hline Healthy weight (18.5-24.9) & $105,618(38.7)$ & $56,710(24.8)$ \\
\hline Overweight (25.0-29.9) & $99,828(36.5)$ & $112,175(49.0)$ \\
\hline Obese (30.0 and above) & $64,282(23.5)$ & $57,888(25.3)$ \\
\hline Waist circumference $(\mathrm{cm})$ (mean (SD)) & $84.7(12.6)$ & $97.0(11.4)$ \\
\hline Waist-to-hip ratio (mean (SD)) & $0.82(0.07)$ & $0.94(0.07)$ \\
\hline Waist-to-height ratio (mean (SD)) & $0.52(0.08)$ & $0.55(0.07)$ \\
\hline History of stroke & $3143(1.2)$ & $4500(2.0)$ \\
\hline \multicolumn{3}{|c|}{ Socioeconomic status (Townsend score thirds): } \\
\hline High & $138,673(50.7)$ & $115,578(50.5)$ \\
\hline Middle & $81,866(30.0)$ & $66,667(29.1)$ \\
\hline Low & $52,396(19.2)$ & $46,423(20.3)$ \\
\hline \multicolumn{3}{|l|}{ Lipids (mmol/L): } \\
\hline Total cholesterol (mean (SD)) & $5.9(1.1)$ & $5.5(1.1)$ \\
\hline $\mathrm{HDL}($ mean $(\mathrm{SD})$ ) & $1.6(0.4)$ & $1.3(0.3)$ \\
\hline LDL (mean (SD)) & $3.6(0.9)$ & $3.5(0.9)$ \\
\hline Elevated cholesterol & $93,062(34.1)$ & $54,507(23.8)$ \\
\hline
\end{tabular}


Table 1 Baseline characteristics of women and men in UK Biobank (Continued)

\begin{tabular}{lll}
\hline Characteristics & Women $(\boldsymbol{n = 2 7 3 , 2 6 2 )}$ & Men $(\boldsymbol{n}=\mathbf{2 2 8 , 9 6 4 )}$ \\
\hline Drug use: & & \\
Antihypertensive drugs & $38,406(14.1)$ & $47,966(20.9)$ \\
Lipid-lowering drugs & $29,503(10.8)$ & $45,731(20.0)$ \\
\hline
\end{tabular}

$S D$ standard deviation, $A H A$ American Heart Association, $H D L$ high-density lipoprotein, $L D L$ low-density lipoprotein

*Defined as diagnosis before the age of 30 and receiving insulin treatment

whereas there was a U-shaped relationship for men. For diastolic blood pressure, there was a clear U-shaped relationship with the risk of dementia for both women and men (Fig. 2). In those without antihypertensive use at baseline $(n=415,854)$, the relationships between blood pressure and the risk of dementia remained similar to the overall association (see Additional file 2).

\section{Smoking}

Compared with never smoking, the HR for current smoking was 1.49 [1.29-1.72] in women and 1.34 [1.191.51] in men; for former smoking, the $\mathrm{HR}$ was 1.04 [0.96-1.12] in women and 1.12 [1.06-1.19] in men. There was no evidence of a sex difference in dementia risk by smoking status nor by smoking intensity.

\section{Diabetes}

For type 1 diabetes, the HR of dementia was 3.12 [1.566.26] in women and 2.86 [1.62-5.04] in men. For type 2 diabetes, the HR was 1.74 [1.49-2.03] in women and $1.92[1.72-2.14]$ in men. There was no evidence of any sex difference.

\section{Adiposity}

The HR for dementia associated with BMI per $5 \mathrm{~kg} / \mathrm{m}^{2}$ was $1.05[1.01-1.10]$ in women and 1.02 [0.97-1.07] in men. For WC, the HR per $10 \mathrm{~cm}$ was 1.08 [1.04-1.12] in women and 1.04 [1.00-1.08] in men. For WHR, the HR per 0.1 was 1.20 [1.12-1.27] in women and 1.13 [1.061.21] in men. For WHTR, the HR per 0.1 was 1.18 [1.11-1.25] in women and 1.17 [1.09-1.24] in men. For BMI categories, the HR for underweight in comparison

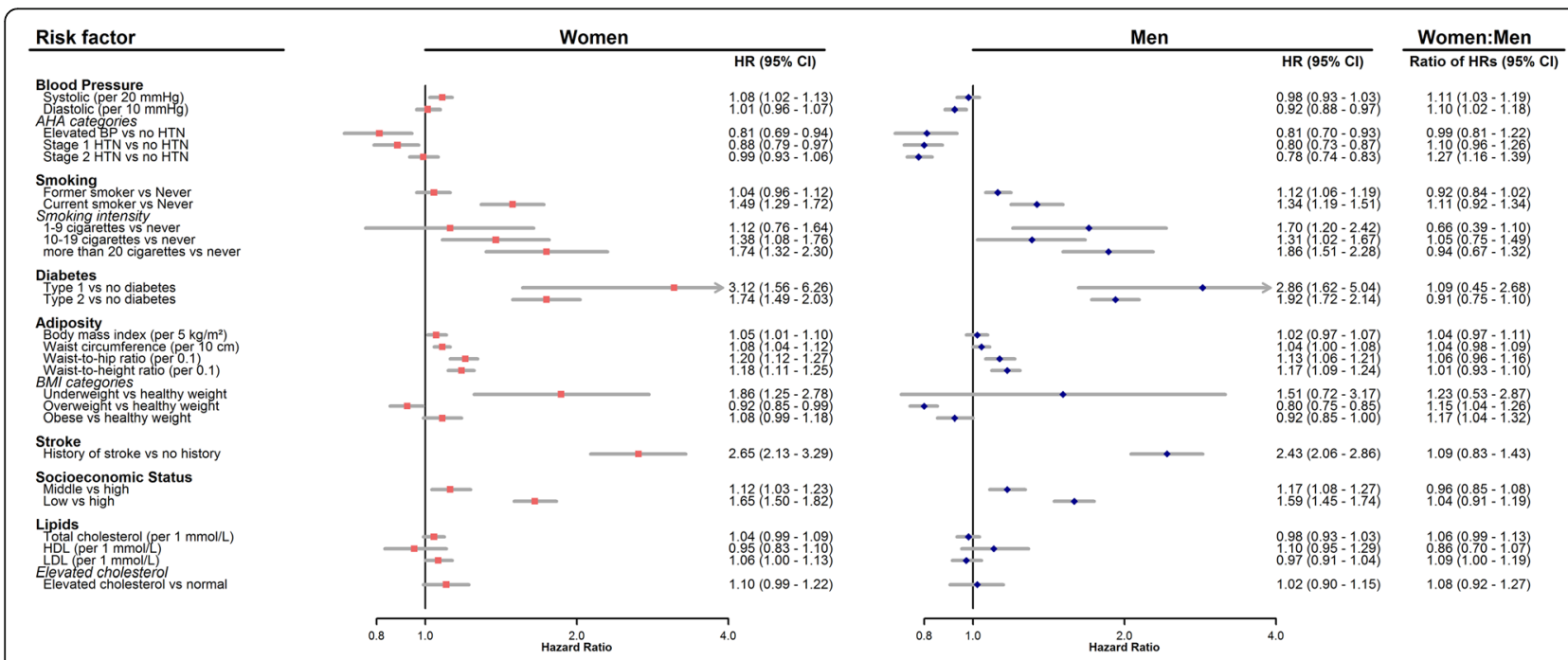

Fig. 1 Sex-specific multiple-adjusted hazard ratios and women-to-men ratio of hazard ratios for risk factors and dementia. $\mathrm{HR}$, hazard ratio; $\mathrm{Cl}$, confidence interval; AHA, American Heart Association; BP, blood pressure; HTN, hypertension; BMI, body mass index; SES, socioeconomic status; $\mathrm{HDL}$, high-density lipoprotein; LDL, low-density lipoprotein. Pink squares represent hazard ratios for women, and blue diamond represent hazard ratios for men, horizontal lines indicate corresponding 95\% confidence intervals around hazard ratios. Hazard ratios for systolic blood pressure is given per $20 \mathrm{mmHg}$ and diastolic blood pressure per $10 \mathrm{mmHg}$; BMl is given per $5 \mathrm{~kg} / \mathrm{m}^{2}$, waist circumference is given per $10 \mathrm{~cm}$, waist-to-hip ratio and waist-to-height ratio are given per 0.1 increase in ratio; lipids are given per $1 \mathrm{mmol} / \mathrm{L}$. Hazard ratios were calculated from separate models with different sets of covariate adjustment. All models were adjusted for age. In addition, SBP, diabetes, socioeconomic status and total cholesterol were adjusted for each other, as well as smoking status, body mass index, lipid-lowering drugs and antihypertensive drugs. Same adjustments were made for DBP and AHA hypertension as for SBP. History of stroke and smoking variables were adjusted for socioeconomic status. Body adiposity variables were adjusted for smoking status and socioeconomic status. HDL, LDL cholesterol and elevated cholesterol were adjusted the same way as total cholesterol 

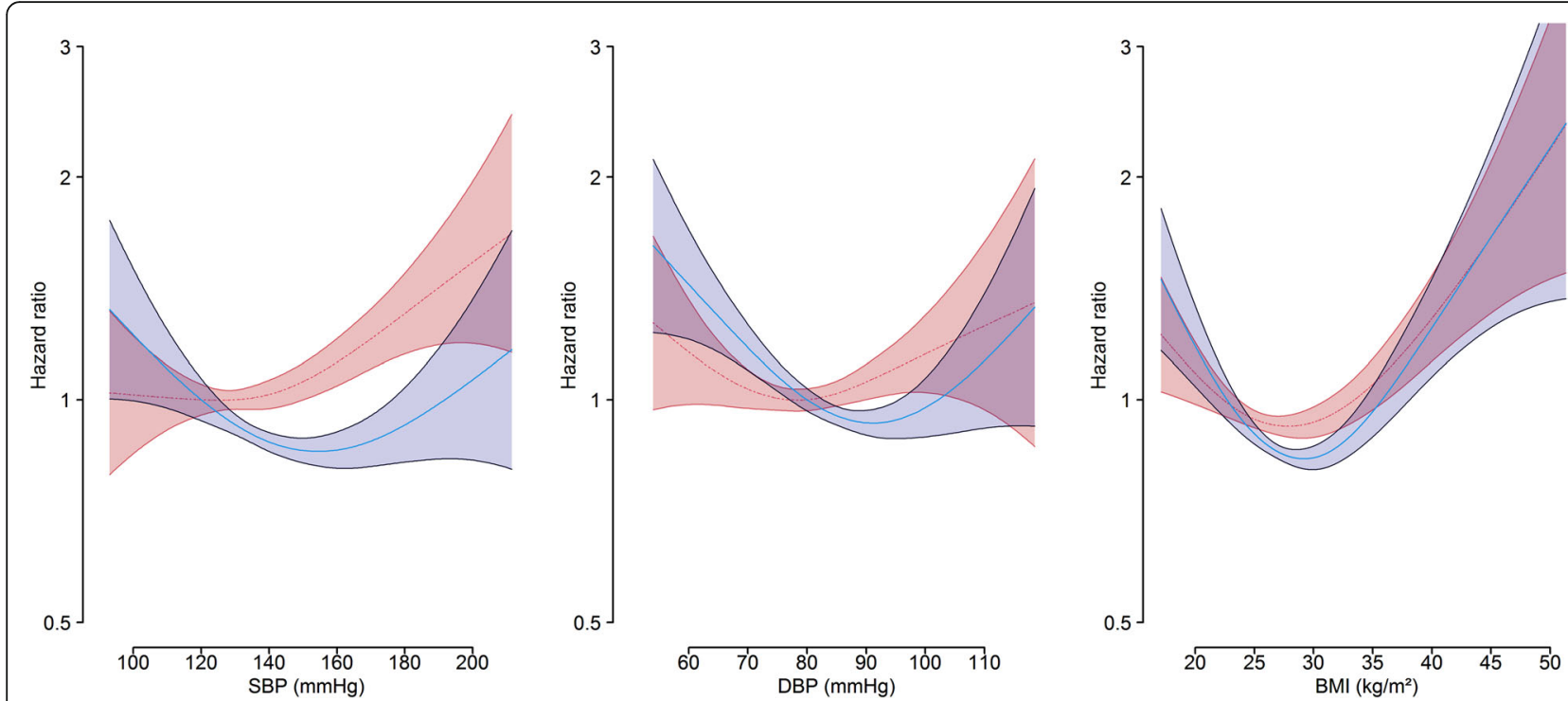

Fig. 2 Sex-specific multiple-adjusted hazard ratios for continuous BMI and blood pressure with the risk of dementia. HR, hazard ratio; SBP, systolic blood pressure; DBP, diastolic blood pressure; BMl, body mass index. Modelled with penalised smoothing splines. Splines for systolic and diastolic blood pressure were adjusted for age, smoking status, body mass index, diabetes status, total cholesterol, socioeconomic status, lipid-lowering drugs and antihypertensive drugs. Splines for BMI were adjusted for age, smoking status, and socioeconomic status. Reference value for systolic blood pressure was $120.0 \mathrm{mmHg}$, and for diastolic blood pressure was $80.0 \mathrm{mmHg}$. The pink dotted line represents the hazard function for women, and the pink shaded area is the $95 \%$ confidence intervals for women; the blue line represents the hazard function for men, and the blue shaded area is the $95 \%$ confidence intervals for men. Extreme values in the upper and lower $0.1 \%$ of the blood pressure distribution were excluded (systolic blood pressure range: $93.0 \mathrm{mmHg}$ to $211.5 \mathrm{mmHg}$; diastolic blood pressure range: $54.0 \mathrm{mmHg}$ to $118.5 \mathrm{mmHg}$ ). Reference value for BMI was $22.5 \mathrm{~kg} / \mathrm{m}^{2}$. The pink dotted line represents the hazard function for women, and the pink shaded area is the $95 \%$ confidence intervals for women; the blue line represents the hazard function for men, and the blue shaded area is the $95 \%$ confidence intervals for men. Extreme values in the upper and lower $0.1 \%$ of the BMl distribution were excluded (BMl range $17.1 \mathrm{~kg} / \mathrm{m}^{2}$ to $51.4 \mathrm{~kg} / \mathrm{m}^{2}$ )

to healthy weight was $1.86[1.25-2.78]$ in women and 1.51 [0.72-3.17] in men, and the HR for overweight was $0.92[0.85-0.99]$ in women and $0.80[0.75-0.85]$ in men; the HR for obese was 1.08 [0.99-1.18] in women and $0.92[0.85-1.00]$ in men. There was evidence for a sex difference among those who were overweight and obese in comparison to a healthy weight, with women in these groups had a greater risk of dementia (women-to-men RHR, 1.15 [1.04-1.26] for overweight, and 1.17 [1.041.32] for obese). The splines revealed J-shaped associations between BMI and the risk of dementia for both women and men (Fig. 2).

\section{Stroke}

The HR for dementia associated with prior stroke was 2.65 [2.13-3.29] in women and 2.43 [2.06-2.86] in men, and there was no evidence for a sex difference.

\section{Socioeconomic status}

Compared with the highest SES, the HR for the lowest SES was 1.65 [1.50-1.82] in women and 1.59 [1.45-1.74] in men, and the HR for the middle SES was 1.12 [1.03$1.23]$ in women and 1.17 [1.08-1.27] in men. No sex difference was evident.

\section{Lipids}

For each of total, HDL and LDL cholesterol, there was no evidence of an association with dementia in women or in men, except for LDL cholesterol in women; the HR was 1.06 [1.00-1.13] per $1 \mathrm{mmol} / \mathrm{L}$ for women whilst this was 0.97 [0.91-1.04] for men, and there was some evidence indicated LDL cholesterol was associated with a greater risk of dementia in women in comparison to men (women-to-men RHR, 1.09 [1.00-1.19]).

The C-statistics from multiple-adjusted Cox models indicated good discrimination of these models (see Additional file 3).

\section{Risk factors by dementia subtypes}

The results for vascular dementia and AD were broadly similar to all-cause dementia (see Additional file 4). There was some evidence indicating that diabetes, smoking and stroke may be more strongly associated with vascular dementia than with $\mathrm{AD}$. The sex difference in the effect of raised BP was consistent for vascular dementia and AD.

\section{Modification by age}

There was no evidence for effect modification of the sex differences by age group ( $\geq 60$ vs $<60$ years), except for 
among those who smoked $\geq 20$ cigarettes per day; it appeared that the risk of dementia was higher in men among the younger age group, while the risk of dementia was higher in women among the older age group $(p=0.03)$ (see Additional file 5).

\section{Modification by socioeconomic status}

There was some evidence of heterogeneity by SES in sex differences between blood pressure (systolic and diastolic) and dementia ( $p=0.03$ for SBP and $p=0.01$ for DBP; see Additional file 6), driven by the comparatively stronger association of blood pressure with dementia among women of higher SES.

\section{Sex comparison of rates of dementia}

The crude incidence rates for dementia was 5.88 [5.62$6.16]$ in women and $8.42[8.07-8.78]$ in men per 10,000 person-years. For all risk factors considered, and for all the categories in these risk factors, the rates of dementia were higher in men than women (Table 2). Unadjusted rates were broadly similar to the multiple-adjusted rates (see Additional file 7).

In addition, the Kaplan-Meier survival curves indicated that the survival probabilities of both death and dementia were lower for men in comparison with women throughout follow-up (see Additional file 8).

\section{Competing risk of death}

The competing risk of death was considered in the analyses, and the results are presented in the supplementary material (see Additional file 9). There were minor differences between the competing risk analysis and the main analysis presented in Fig. 1. Most notably, the ratios of sub-distribution hazard ratios for BMI categories were no longer significant compared with our main analysis.

\section{Discussion}

This study of over half a million participants in the UK Biobank assessed the presence of sex differences in major cardiovascular risk factors and the risk of incident all-cause dementia. On average, men have more adverse cardiovascular profile compared with women at the study baseline. Current smoking, type 1 and type 2 diabetes, high adiposity, stroke and low SES were each associated with increased risk of dementia, similarly in women and men. While the rates of dementia were higher in men than women at all levels considered, the relationship between blood pressure and dementia was U-shaped in men but had a dose-response relationship in women, and this difference appeared to be restricted to those of higher SES.

\section{Blood pressure}

High blood pressure has been consistently linked to dementia and impairment of some cognitive domains [15, 16], but few studies have evaluated potential sex differences, with mixed empirical results [17-21]. A study of included members of the Kaiser Permanente Northern California (KPNC) found that midlife hypertension was associated with a higher risk of dementia in women only [17]; with two other studies also reporting that hypertension was associated with vascular dementia [18] and mild cognitive impairment [19] in women but not in men. Our study not only used guideline-based definitions to categorise hypertension, blood pressures were also included as continuous measures, offering insights to more precise blood pressure targets in improving cognitive health.

Several mechanisms may provide some explanations for the sex differences between blood pressure and dementia observed in our study. First, women may have better cerebral autoregulation than men [22], and reduced cerebral perfusion in men may be associated with a higher incidence of orthostatic hypotension hospitalisation [22], which has been associated with a greater risk of dementia [23]. Second, sex differences in medical treatment are possible. Previous studies reported that treatment adherence was generally lower in women than men, which was in part explained by greater polypharmacy and more side effects in women [24].

\section{Smoking}

Cardiovascular pathology is thought to underlie the increased risk of cognitive impairment and dementia among smokers [3], although smokers also have a higher risk of premature death, precluding them from reaching the age at which dementia might develop; as such, potential uncertainty exists in determining this relationship [3]. Similar to our study, a meta-analysis examined the effects of cigarette smoking on dementia showed that current smokers had a greater risk of all-cause dementia, vascular dementia and $\mathrm{AD}$, but not for former smoker when compared with never smokers [25]. Studies that accounted for the competing risk of death found that the effect of smoking attenuated [26]. Our competing risk analysis indicated that in comparison to never smokers, current smokers and smoking more than 20 cigarettes per day remain to be strong risk factors for all-cause dementia in both women and men. Further clarification is necessary for smoking as a risk factor for dementia.

\section{Diabetes}

A previous meta-analysis found that type 2 diabetes was associated with a $60 \%$ increased risk of any dementia in both sexes [27]. Similarly, the present study showed that 
Table 2 Sex-specific multiple-adjusted rates of dementia and women-to-men difference of rate differences for each risk factor

\begin{tabular}{|c|c|c|c|}
\hline \multirow[t]{2}{*}{ Variables } & \multicolumn{2}{|c|}{ Rates/10,000 person years $(95 \% \mathrm{Cl})$} & \multirow{2}{*}{$\begin{array}{l}\text { Difference of rate } \\
\text { differences }(95 \% \\
\mathrm{Cl})\end{array}$} \\
\hline & Women $(n=273,262)$ & Men $(n=228,964)$ & \\
\hline \multicolumn{4}{|l|}{ AHA hypertension categories: } \\
\hline Normal & $6.43(5.49,7.37)$ & $8.71(7.32,10.11)$ & - \\
\hline Elevated & $5.23(4.43,6.02)$ & $7.24(6.20,8.27)$ & $-0.27(-2.37,1.82)$ \\
\hline Stage 1 hypertension & $5.69(5.10,6.28)$ & $7.17(6.49,7.85)$ & $-0.80(-2.68,1.08)$ \\
\hline Stage 2 hypertension & $6.44(6.00,6.87)$ & $7.05(6.63,7.47)$ & $-1.67(-3.45,0.11)$ \\
\hline \multicolumn{4}{|l|}{ Smoking status: } \\
\hline Never smoker* & $5.78(5.42,6.13)$ & $7.27(6.77,7.76)$ & - \\
\hline Former smoker & $5.92(5.46,6.38)$ & $7.99(7.50,8.47)$ & $0.57(-0.33,1.48)$ \\
\hline Current smoker & $8.11(6.93,9.29)$ & $8.98(7.89,10.06)$ & $-0.63(-2.35,1.09)$ \\
\hline \multicolumn{4}{|c|}{ Smoking intensity (average number of cigarettes smoked daily): } \\
\hline Never smoker** & $5.19(4.87,5.51)$ & $6.53(6.08,6.97)$ & - \\
\hline $1-9$ cigarettes & $5.58(3.43,7.72)$ & $10.47(6.78,14.17)$ & $3.56(-0.75,7.87)$ \\
\hline 10-19 cigarettes & $6.76(5.09,8.43)$ & $7.82(5.86,9.77)$ & $-0.28(-2.91,2.36)$ \\
\hline 20 cigarettes & $8.19(5.91,10.47)$ & $10.56(8.37,12.75)$ & $1.04(-2.18,4.25)$ \\
\hline \multicolumn{4}{|l|}{ Diabetes: } \\
\hline No diabetes & $5.78(5.46,6.10)$ & $6.74(6.39,7.08)$ & - \\
\hline Type $1^{\#}$ & $15.74(4.77,26.71)$ & $17.63(7.58,27.67)$ & $0.93(-13.96,15.81)$ \\
\hline Type 2 & $9.72(8.12,11.33)$ & $12.34(10.80,13.89)$ & $1.66(-0.62,3.94)$ \\
\hline \multicolumn{4}{|l|}{ Body mass index: } \\
\hline Healthy weight (18.5-24.9) & $6.03(5.55,6.50)$ & $8.68(7.97,9.40)$ & - \\
\hline Underweight (< 18.5) & $10.52(6.30,14.73)$ & $10.68(2.75,18.60)$ & $-2.50(-11.51,6.52)$ \\
\hline Overweight (25.0-29.9) & $5.57(5.15,6.00)$ & $7.01(6.57,7.46)$ & $-1.22(-2.27,-0.16)$ \\
\hline Obese (30.0 and above) & $6.67(6.09,7.24)$ & $8.16(7.50,8.82)$ & $-1.16(-2.39,0.07)$ \\
\hline \multicolumn{4}{|l|}{ Stroke: } \\
\hline None & $5.87(5.60,6.14)$ & $7.52(7.19,7.85)$ & - \\
\hline History of stroke & $14.64(11.51,17.76)$ & $17.05(14.36,19.74)$ & $0.76(-3.38,4.91)$ \\
\hline \multicolumn{4}{|l|}{ Townsend score thirds: } \\
\hline High & $5.37(4.97,5.77)$ & $6.35(5.93,6.77)$ & - \\
\hline Middle & $5.98(5.43,6.52)$ & $7.30(6.68,7.92)$ & $0.34(-0.65,1.32)$ \\
\hline Low & $8.69(7.85,9.53)$ & $9.60(8.70,10.51)$ & $-0.07(-1.42,1.29)$ \\
\hline \multicolumn{4}{|l|}{ Lipids: } \\
\hline Normal cholesterol & $6.04(5.66,6.42)$ & $7.33(6.95,7.70)$ & - \\
\hline Elevated cholesterol & $6.58(6.08,7.08)$ & $7.91(7.22,8.59)$ & $0.04(-0.98,1.06)$ \\
\hline
\end{tabular}

AHA American Heart Association

All models were adjusted for age. Hypertension was adjusted for smoking status, total cholesterol, body mass index, diabetes, socioeconomic status, lipid-lowering drugs and antihypertensive drugs. Diabetes was adjusted for smoking status, body mass index, systolic blood pressure, total cholesterol, socioeconomic status, lipid-lowering drugs and antihypertensive drugs. Socioeconomic status was adjusted for smoking status, systolic blood pressure, total cholesterol, body mass index, diabetes, lipid-lowering drugs and antihypertensive drugs. Body mass index was adjusted for smoking status and socioeconomic status. Elevated cholesterol was adjusted for smoking status, systolic blood pressure, body mass index, socioeconomic status, lipid-lowering drugs and antihypertensive drugs *Models for smoking status $\left(^{*}\right)$ and smoking intensity $\left(^{* *}\right)$ were fitted using different variables, given the model for smoking intensity excluded former smokers and those with missing cigarette consumption, and thus produced slightly different multiple-adjusted rates of dementia for the never smoker category compared to the rates in the model for smoking status

\#Defined as diagnosis before the age of 30 and receiving insulin treatment

compared to no diabetes, type 1 and type 2 diabetes were associated with an increased risk of dementia in both women and men. The link between diabetes and dementia is alarming, with the number of people with diabetes projected to increase to 68,000 by 2027 in the UK Biobank [10], as it is increasing globally [28]. While 
routine screening for cognitive dysfunctions in diabetes is necessary [29], novel treatment options and prevention strategies are crucial for reducing the burden of dementia in this at-risk population.

\section{Body adiposity}

The relationship between body adiposity and dementia is complex and appear to be non-linear depending on dementia subtypes [30]. Our recent meta-analysis, with the inclusion of data from the UK Biobank, showed comparable findings where underweight (BMI $<18.5 \mathrm{~kg} /$ $\mathrm{m}^{2}$ ) was strongly associated with the risk of both vascular and non-vascular dementia [30]. Although no sex difference was reported in the meta-analysis, these effects were only significant in women [30]. Underweight is an important subclinical consequence of prodromal dementia, such that the possibility of reverse causality cannot be ruled out.

\section{Stroke}

A previous meta-analysis showed that female sex was associated with a $30 \%$ greater risk for post-stroke dementia, although this may have been influenced by women's older age [31]. While there was no evidence for a sex difference in the effects of stroke in the present study, a history of stroke was associated with more than double the risk of dementia in both sexes. Our results complement the joint call for action by the World Stroke Organisation in prevention for stroke and dementia [32], as it was estimated that more than a third of dementia could be prevented by preventing stroke [32].

\section{Socioeconomic status}

The Three-City Study found that women living in deprived neighbourhoods have a greater risk of dementia, but not men [33]. Another study concluded that lower educational attainment was independently associated with a greater risk of dementia death in women, after considering other comorbidities and behaviours [34]. Given deprivation was associated with the risk of dementia to a similar extent in women and men, reducing socioeconomic inequities may thus have significant effects on dementia prevention, as well as many other conditions on a population level.

\section{Lipids}

The evidence for lipids as risk factors for dementia has been mixed, with a meta-analysis suggesting that high total cholesterol in midlife is associated with a greater risk of developing $\mathrm{AD}$ [35]. A recent meta-meta-analysis, which explored the effect of cholesterol fractions concluded that LDL cholesterol increased the risk of $\mathrm{AD}$, while HDL and total cholesterol showed a nonsignificant association with AD risk [36]. A Mendelian
Randomisation study confirmed that high circulating total cholesterol and a reduced level of HDL cholesterol might be associated with an increased risk of AD [37]. Our results do not support such associations.

\section{Strengths and limitations of the study}

To our knowledge, this study is the first to systematically evaluate sex differences in a range of cardiovascular risk factors for dementia in a large general population, using standardised methodology. This study was further strengthened by its prospective cohort design and large sample size. Sex differences were compared on both relative and absolute scales, providing insights to inform public health and clinical practice in risk reduction for dementia. This study also has limitations. The UK Biobank cohort is a relatively healthy and affluent population, predominantly of Caucasian ancestry, which may limit the generalisability of the results. Self-reported smoking, diabetes and history of stroke may be subject to reporting bias. Multiple testing of interactions can raise the concern of false positives. With the threshold of $5 \%$, one significant test would be expected in every 20 tests performed, even if there were no real effects. Thus, our results should be interpreted with caution. Lastly, while we were able to distinguish the effects of blood pressure by baseline antihypertensive use, we had no further information on medication use duration or dose, hence limiting our ability to interpret the results.

\section{Conclusions}

Several cardiovascular risk factors were found to be associated with incident dementia in both sexes. Despite the rate of incident dementia being higher in men compared to women, raised blood pressure was associated with a greater relative risk of dementia in women than equivalent men. Given the lack of proven pharmaceutical treatments for dementia, public health strategies to promote healthy lifestyles are important to reduce the burden of dementia. Among trials aim to prevent cognitive decline or dementia, the strongest evidence lies in treating hypertension [3]. However, findings from this research suggests this is not sufficient and warrants further work to identify factors associated with relative poverty that is also important. Assuming causality, bespoke randomised control trials of blood pressure lowering are necessary, to understand its role in attenuating cognitive decline, and such trials should include an equal number of women and men in order to clarify potential sex differences.

\footnotetext{
Abbreviations

AD: Alzheimer's disease; AHA: American Heart Association; BMI: Body mass index; BP: Blood pressure; Cl: Confidence interval; DBP: Diastolic blood pressure; HDL: High-density lipoproteins; HR: Hazard ratio; ICD: International Classification of Disease; LDL: Low-density lipoproteins; RHR: Ratio of hazard
} 
ratios; SBP: Systolic blood pressure; SD: Standard deviation;

SES: Socioeconomic status; WC: Waist circumference; WHR: Waist to hip ratio; WHTR: Waist to height ratio

\section{Supplementary Information}

The online version contains supplementary material available at https://doi. org/10.1186/s12916-021-01980-z.

Additional file 1. Age-adjusted hazard ratios and ratio of the hazard ratios (women-to-men) for risk factors and dementia, by sex.

Additional file 2. Multiple adjusted hazard ratios for systolic and diastolic blood pressure and dementia disaggregated by antihypertensive use, by sex.

Additional file 3. Multiple-adjusted C-statistics with standard errors (se) for each risk factor in association with all-cause dementia.

Additional file 4. Multiple-adjusted hazard ratios and ratio of the hazard ratios (women-to-men) for risk factors and by dementia subtypes.

Additional file 5. Multiple-adjusted hazard ratios and women-to-men ratio of hazard ratios for risk factors and dementia, by age group and sex.

Additional file 6. Multiple adjusted hazard ratios (HRs) and 95\% confidence intervals $(\mathrm{Cl})$ for the association between risk factors and incident dementia, by socioeconomic status (SES) and sex.

Additional file 7. Unadjusted rates of incident dementia (per 10,000 person years) by sex, and women-to-men difference of rate differences for each risk factor.

Additional file 8. Kaplan-Meier survival curves for death and dementia, by sex.

Additional file 9. Multiple-adjusted sub-distribution hazard ratios (SHR) and ratio of the sub-distribution hazard ratios (women-to-men) for risk factors for dementia from competing risks analysis.

\section{Acknowledgements}

We thank the UK Biobank participants that contributed to this valuable resource.

\section{Authors' contributions}

All authors were involved in the design of the study. JG and $\mathrm{KH}$ carried out the statistical analyses, with support from SAEP and MW. JG wrote the first draft of the manuscript. All authors edited further drafts and approved the final draft of the manuscript. The corresponding author attests that all listed authors meet authorship criteria and that no others meeting the criteria have been omitted. MW is the guarantor of the work.

\section{Funding}

JG is supported by the Scientia PhD scholarship from the University of New South Wales, Sydney, Australia. SAEP is supported by a UK Medical Research Council Skills Development Fellowship (MR/P014550/1). MW is supported by an Australian National Health and Medical Research Council Investigator Grant (APP1174120) and Program Grant (APP1149987). The funders had no role in the study design, collection, analysis, interpretation of data, writing of the manuscript or in the decision to submit the article for publication.

\section{Availability of data and materials}

The data used in this current study are available from the UK Biobank data resources. Permissions are required in order to gain access to the UK Biobank data resources, subject to successful registration and application process. Further information can be found on the UK Biobank website (https://www.ukbiobank.ac.uk/).

\section{Declarations}

\section{Ethics approval and consent to participate}

UK Biobank has obtained Research Tissue Bank approval from its governing Research Ethics Committee, as recommended by the National Research Ethics Service. This research has been conducted using the UK Biobank Resource (application No. 2495). Permission to use the UK Biobank Resource was approved by the access subcommittee of the UK Biobank Board. Written informed consent was obtained for all participants electronically.

\section{Consent for publication}

Not applicable.

\section{Competing interests}

All authors have completed the Unified Competing Interest form and declare: no support from any organisation for the submitted work; MW does consultancy for Amgen, Freeline and Kirin outside the submitted work; no other relationships or activities that could appear to have influenced the submitted work

\section{Author details}

${ }^{1}$ The George Institute for Global Health, University of New South Wales, Leve 5, 1 King St, Newtown, NSW 2042, Australia. ${ }^{2}$ The George Institute for Global Health, Imperial College London, Central Working - Fourth Floor, Translation and Innovation Hub, Imperial College London, 80 Wood Lane, London W12 OBZ, UK. ${ }^{3}$ Julius Center for Health Sciences and Primary Care, University Medical Center Utrecht, Utrecht University, PO Box 85500, 3508, GA, Utrecht, The Netherlands. ${ }^{4}$ Welch Center for Prevention, Epidemiology and Clinical Research, Johns Hopkins University, Baltimore, MD, USA.

Received: 17 January 2021 Accepted: 7 April 2021

Published online: 19 May 2021

\section{References}

1. Nichols E, Szoeke CE, Vollset SE, Abbasi N, Abd-Allah F, Abdela J, et al. Global, regional, and national burden of Alzheimer's disease and other dementias, 1990-2016: a systematic analysis for the Global Burden of Disease Study 2016. Lancet Neurol. 2019;18(1):88-106. https://doi.org/10.101 6/S1474-4422(18)30403-4.

2. Prince MJ. World Alzheimer Report 2015: the global impact of dementia: an analysis of prevalence, incidence, cost and trends. London: Alzheimer's Disease International (ADI); 2015.

3. Livingston G, Huntley J, Sommerlad A, Ames D, Ballard C, Banerjee S, et al. Dementia prevention, intervention, and care: 2020 report of the lancet commission. Lancet. 2020;396(10248):413-46. https://doi.org/10.1016/S01406736(20)30367-6.

4. World Health Organization. The epidemiology and impact of dementia. Geneva: World Health Organization; 2019.

5. Gottesman RF, Albert MS, Alonso A, Coker LH, Coresh J, Davis SM, et al. Associations between midlife vascular risk factors and 25-year incident dementia in the Atherosclerosis Risk in Communities (ARIC) cohort. JAMA Neurol. 2017;74(10):1246-54. https://doi.org/10.1001/jamaneurol.2017.1658

6. Gottesman RF, Schneider AL, Zhou Y, Coresh J, Green E, Gupta N, et al. Association between midlife vascular risk factors and estimated brain amyloid deposition. Jama. 2017;317(14):1443-50. https://doi.org/10.1001/ja ma.2017.3090.

7. Millett ER, Peters SA, Woodward M. Sex differences in risk factors for myocardial infarction: cohort study of UK Biobank participants. BMJ. 2018; 363:k4247.

8. Peters SA, Carcel C, Millett ER, Woodward M. Sex differences in the association between major risk factors and the risk of stroke in the UK Biobank cohort study. Neurology. 2020;95(20):e2715-26. https://doi.org/1 0.1212 WNL.0000000000010982.

9. Mauvais-Jarvis F, Merz NB, Barnes PJ, Brinton RD, Carrero JJ, DeMeo DL, et al. Sex and gender: modifiers of health, disease, and medicine. Lancet. 2020; 396(10250):565-82. https://doi.org/10.1016/S0140-6736(20)31561-0.

10. Sudlow C, Gallacher J, Allen N, Beral V, Burton P, Danesh J, et al. UK biobank: an open access resource for identifying the causes of a wide range of complex diseases of middle and old age. PLoS Med. 2015;12(3):e1001779. https://doi.org/10.1371/journal.pmed.1001779.

11. Whelton PK, Carey RM, Aronow WS, Casey DE, Collins KJ, Dennison Himmelfarb C, et al. 2017 ACC/AHA/AAPA/ABC/ACPM/AGS/APhA/ASH/ ASPC/NMA/PCNA guideline for the prevention, detection, evaluation, and management of high blood pressure in adults: a report of the American College of Cardiology/American Heart Association Task Force on Clinical Practice Guidelines. J Am Coll Cardiol. 2018;71(19):e127-248. https://doi. org/10.1016/j.jacc.2017.11.006. 
12. Townsend P. Deprivation. J Soc Policy. 1987;16(2):125-46. https://doi.org/1 $0.1017 / 50047279400020341$.

13. Woodward M. Rationale and tutorial for analysing and reporting sex differences in cardiovascular associations. Heart. 2019;105(22):1701-8. https://doi.org/10.1136/heartjnl-2019-315299.

14. Fine JP, Gray RJ. A proportional hazards model for the subdistribution of a competing risk. J Am Stat Assoc. 1999;94(446):496-509. https://doi.org/10.1 080/01621459.1999.10474144

15. Hughes D, Judge C, Murphy R, Loughlin E, Costello M, Whiteley W, et al. Association of blood pressure lowering with incident dementia or cognitive impairment: a systematic review and meta-analysis. JAMA. 2020;323(19): 1934-44. https://doi.org/10.1001/jama.2020.4249.

16. Veldsman M, Tai XY, Nichols T, Smith S, Peixoto J, Manohar S, Husain M. Cerebrovascular risk factors impact frontoparietal network integrity and executive function in healthy ageing. Nat Commun 2020;11(1):1-0, 4340, doi: https://doi.org/10.1038/s41467-020-18201-5.

17. Gilsanz P, Mayeda ER, Glymour MM, Quesenberry CP, Mungas DM, DeCarli $C$, et al. Female sex, early-onset hypertension, and risk of dementia. Neurology. 2017;89(18):1886-93. https://doi.org/10.1212/WNL. 0000000000004602.

18. Hébert R, Lindsay J, Verreault R, Rockwood K, Hill G, Dubois MF. Vascular dementia: incidence and risk factors in the Canadian study of health and aging. Stroke. 2000;31 (7):1487-93. https://doi.org/10.1161/01.STR.31.7.1487.

19. Pankratz VS, Roberts RO, Mielke MM, Knopman DS, Jack CR, Geda YE, et al. Predicting the risk of mild cognitive impairment in the Mayo Clinic Study of Aging. Neurology. 2015;84(14):1433-42. https://doi.org/10.1212/WNL. 0000000000001437.

20. Whitmer RA, Sidney S, Selby J, Johnston SC, Yaffe K. Midlife cardiovascular risk factors and risk of dementia in late life. Neurology. 2005;64(2):277-81. https://doi.org/10.1212/01.WNL.0000149519.47454.F2.

21. Kimm H, Lee PH, Shin YJ, Park KS, Jo J, Lee Y, et al. Mid-life and late-life vascular risk factors and dementia in Korean men and women. Arch Gerontol Geriatr. 2011;52(3):e117-22. https://doi.org/10.1016/j.archger.2010 09.004 .

22. Deegan BM, Sorond FA, Galica A, Lipsitz LA, O'Laighin G, Serrador JM. Elderly women regulate brain blood flow better than men do. Stroke. 2011; 42(7):1988-93. https://doi.org/10.1161/STROKEAHA.110.605618.

23. Wolters FJ, Zonneveld HI, Hofman A, van der Lugt A, Koudstaal PJ, Vernooij MW, et al. Cerebral perfusion and the risk of dementia: a population-based study. Circulation. 2017;136(8):719-28. https://doi.org/10.1161/CIRCULA TIONAHA.117.027448.

24. Manteuffel M, Williams S, Chen W, Verbrugge RR, Pittman DG, Steinkellner A. Influence of patient sex and gender on medication use, adherence, and prescribing alignment with guidelines. J Women's Health. 2014;23(2):112-9. https://doi.org/10.1089/jwh.2012.3972.

25. Zhong G, Wang Y, Zhang Y, Guo JJ, Zhao Y. Smoking is associated with an increased risk of dementia: a meta-analysis of prospective cohort studies with investigation of potential effect modifiers. Plos One. 2015;10(3): e0118333. https://doi.org/10.1371/journal.pone.0118333.

26. Abner EL, Nelson PT, Jicha GA, Cooper GE, Fardo DW, Schmitt FA, et al. Tobacco smoking and dementia in a Kentucky cohort: a competing risk analysis. J Alzheimers Dis. 2019;68(2):625-33. https://doi.org/10.3233/JAD-1 81119.

27. Chatterjee S, Peters SA, Woodward M, Arango SM, Batty GD, Beckett N, et al. Type 2 diabetes as a risk factor for dementia in women compared with men: a pooled analysis of 2.3 million people comprising more than 100,000 cases of dementia. Diabetes Care. 2016;39(2):300-7. https://doi.org/10.2337/ dc15-1588.

28. Saeedi P, Petersohn I, Salpea P, Malanda B, Karuranga S, Unwin N, et al. Global and regional diabetes prevalence estimates for 2019 and projections for 2030 and 2045: results from the International Diabetes Federation Diabetes Atlas. Diab Res Clin Pract. 2019:157:107843.

29. Biessels GJ, Whitmer RA. Cognitive dysfunction in diabetes: how to implement emerging guidelines. Diabetologia. 2020;63(1):3-9. https://doi. org/10.1007/s00125-019-04977-9.

30. Lee CM, Woodward M, Batty GD, Beiser AS, Bell S, Berr C, et al. Association of anthropometry and weight change with risk of dementia and its major subtypes: a meta-analysis consisting 2.8 million adults with 57294 cases of dementia. Obes Rev. 2020;21(4):e12989.

31. Pendlebury ST, Rothwell PM. Prevalence, incidence, and factors associated with pre-stroke and post-stroke dementia: a systematic review and meta- analysis. Lancet Neurol. 2009;8(11):1006-18. https://doi.org/10.1016/S14 74-4422(09)70236-4.

32. Hachinski V, Einhäupl K, Ganten D, Alladi S, Brayne C, Stephan BC, et al. Preventing dementia by preventing stroke: the Berlin Manifesto. Alzheimers Dement. 2019;15(7):961-84. https://doi.org/10.1016/j.jalz.2019.06.001.

33. Letellier N, Gutierrez LA, Carrière I, Gabelle A, Dartigues JF, Dufouil C, et al. Sex-specific association between neighborhood characteristics and dementia: the Three-City cohort. Alzheimers Dement. 2018;14(4):473-82. https://doi.org/10.1016/j.jalz.2017.09.015.

34. Russ TC, Stamatakis E, Hamer M, Starr JM, Kivimäki M, Batty GD. Socioeconomic status as a risk factor for dementia death: individual participant meta-analysis of 86508 men and women from the UK. Br J Psychiatry. 2013;203(1):10-7. https://doi.org/10.1192/bjp.bp.112.119479.

35. Anstey KJ, Ashby-Mitchell K, Peters R. Updating the evidence on the association between serum cholesterol and risk of late-life dementia: review and meta-analysis. J Alzheimers Dis. 2017;56(1):215-28. https://doi.org/1 $0.3233 / J A D-160826$

36. Sáiz-Vazquez O, Puente-Martínez A, Ubillos-Landa S, Pacheco-Bonrostro J, Santabárbara J. Cholesterol and Alzheimer's disease risk: a meta-metaanalysis. Brain Sci. 2020;10(6):386. https://doi.org/10.3390/brainsci10060386.

37. Zhang X, Tian $Q$, Liu D, Geng T, Xu X, Ge S, et al. Causal association of circulating cholesterol levels with dementia: a mendelian randomization meta-analysis. Transl Psychiatry. 2020;10(1):1-8.

\section{Publisher's Note}

Springer Nature remains neutral with regard to jurisdictional claims in published maps and institutional affiliations.
Ready to submit your research? Choose BMC and benefit from:
- fast, convenient online submission
- thorough peer review by experienced researchers in your field
- rapid publication on acceptance
- support for research data, including large and complex data types
- gold Open Access which fosters wider collaboration and increased citations
- maximum visibility for your research: over $100 \mathrm{M}$ website views per year
At BMC, research is always in progress.
Learn more biomedcentral.com/submissions 